\title{
Prediction of reference evapotranspiration using artificial neural network
}

R.V. MESHRAM, M.M. DESHMUKH, S.B. WADATKAR, M.U. KALE AND A.N. MANKAR

Received : 22.04.2014; Revised : 01.02.2015; Accepted : 15.02.2015

See end of the Paper for authors' affiliation

Correspondence to :

M.M. DESHMUKH

Department of Irrigation and Drainage Engineering, Dr. Panjabrao Deshmukh Krishi Vidyapeeth, AKOLA (M.S.) INDIA

Email : mahendradeshmukh@ yahoo.com
-ABSTRACT : The study has been undertaken to predict one month ahead ETo using artificial neural networks (ANNs). Climatic parameters for 35 years (1977-2011) were collected for Akola station. The ETo was estimated by using standard Penman-Monteith method which was further used for development and validation of the ANN models as the observed data on ETo was not available. The ANN models were developed using different input combinations. The models learned to predict one month ahead ETo (i.e. $\mathrm{ET}_{\mathrm{o}, \mathrm{t}+1}$ ) for Akola using Levenberg-Marquardt learning method. The training results were compared with each other, and performance evaluations were done for untrained data. Based on results obtained, the ANN model with architecture of 4-12-1 (four, twelve and one neuron(s) in the input, hidden, and output layers, respectively) was found to be the best amongst all the models with minimum standard error (SE) of estimates of $0.74 \mathrm{~mm}^{-1} \mathrm{y}^{-1}$ and correlation co-efficient of 0.9260 . From the study it is concluded that ANN4 model had given better performance with mean absolute error of estimates (MAE) and root mean square error (RMSE) of 0.20 and 0.27 mm day ${ }^{-1}$, respectively, mean absolute relative error (MARE) of 5.7 per cent and model efficiency of 0.9745 .

- KEY WORDS : Reference evapotranspiration, ANN, Levenberg-Marquardt

- HOW TO CITE THIS PAPER : Meshram, R.V., Deshmukh, M.M., Wadatkar, S.B., Kale, M.U. and Mankar, A.N. (2015). Prediction of reference evapotranspiration using artificial neural network. Internat. J. Agric. Engg., 8(1) : 1-8. 